\title{
Análise dos Métodos de Ensino utilizados nas disciplinas de Sistemas de Informações nos cursos de graduação em Administração e Ciências Contábeis
}

\author{
Antônio Artur de Souza ${ }^{1}$, Ana Carolina Neves de Araújo2², Mariana Guerra3 ${ }^{3}$ \\ ${ }^{1}$ Universidade Federal de Minas Gerais \\ ${ }^{2}$ Universidade Federal de Minas Gerais \\ ${ }^{3}$ Universidade Federal de Minas Gerais \\ artur@face.ufmg.br, carolna@face.ufmg.br, mariguerra@face.ufmg.br
}

\begin{abstract}
Resumo. Este artigo apresenta os resultados de uma pesquisa que teve como objetivo analisar os métodos de ensino utilizados para lecionar disciplinas relacionadas com Sistemas de Informações (SIs) nos cursos de graduação em Administração (ADM) e Ciências Contábeis (CIC) na Universidade Federal de Minas Gerais. Para tanto, procurou-se apresentar uma discussão sobre o conteúdo, a carga horária e os métodos de ensino empregados nas disciplinas relacionadas com SIs nos dois cursos. Os dados foram coletados por meio de entrevistas com os professores das disciplinas e os coordenadores. Além disso, aplicou-se um questionário aos alunos que cursam essas disciplinas nos dois cursos. Os resultados apontam que uma das principais limitações para lecionar as disciplinas é a precária disponibilização de recursos físicos e a dificuldade em conciliar o interesse dos alunos com atividades e métodos de ensino. A maioria dos entrevistados apontou a relevância das disciplinas de SIs para a formação profissional de administradores e contadores. Uma necessidade destacada pelos entrevistados foi a importância da inter-ligação das disciplinas de SIs com aquelas de outras áreas.
\end{abstract}

\section{Introdução}

No ambiente globalizado em que estão inseridas as empresas atualmente, a necessidade por informações rápidas e confiáveis é cada vez maior. Para suprir essa demanda, as empresas buscam utilizar Sistemas de Informações (SIs) que consigam coletar, armazenar e processar dados, gerando informações de qualidade para a tomada de decisão de forma eficaz. Os SIs são empregados não apenas para reduzir custos e maximizar resultados, mas também para auxiliar na busca e definição de estratégias que visem alcançar posições competitivas para as empresas. Dessa forma, as empresas que atuam em tais setores exigem maior qualificação de sua mão-de-obra.

Os profissionais que atuam nesse ambiente competitivo devem capacitar-se para gerir com eficiência e eficácia as informações necessárias ao processo decisório. E, além de profissionais capacitados, é necessário que esses estejam amparados por uma infra-estrutura que os auxiliem no processo decisório. Pressupõe-se indispensável, para 
isso, conhecimento sobre SIs e áreas técnicas essenciais para a tomada de decisão (Administração, Contabilidade, Economia, Estatística, Direito, Matemática Financeira etc.).

Considerando tal cenário, as empresas esperam que esses profissionais possam instruir-se com uma educação de qualidade, que contemple conteúdos de SIs e demais conhecimentos necessários à tomada de decisão. Segundo Souza (2001), quando o tomador de decisões age motivado pela intuição, mesmo que os resultados decorrentes desta ação sejam os mais favoráveis, a empresa não poderá legitimar este procedimento como o mais indicado. A verdade é que não se pode apreender com o êxito se este foi conseguido sem a observância de passos lógicos bem estruturados. Porém, como definir ensino de qualidade? Além disso, como lecionar tais conteúdos de forma eficaz? As universidades preparam os futuros profissionais para atender a demanda do mercado?

A forma como os conteúdos de SIs são ensinados aos futuros profissionais influencia a qualidade da educação, e conseqüentemente de sua atuação no mercado. Por isso, é necessário avaliar quais métodos de ensino são mais eficientemente aplicáveis a área de negócios no ensino de SIs, para garantir uma boa formação a administradores e contadores.

O objetivo principal deste artigo é analisar os métodos de ensino utilizados para lecionar disciplinas de Sistemas de Informações nos cursos de graduação em Administração e Ciências Contábeis na Universidade Federal de Minas Gerais. Para tanto, será apresentada uma discussão sobre conteúdo, carga horária e métodos de ensino empregados nas disciplinas de SIs nos dois cursos. A relevância do tema da pesquisa deve-se a importância dos SIs para a formação profissional em Administração e Contabilidade. Esses profissionais que atuam no mercado como tomadores de decisão, necessitam ser amparados por ferramentas que os auxiliem na análise de dados para a produção de informações, nas quais se baseia o processo decisório..Os SIs configuramse como uma dessas ferramentas essenciais a uma gestão eficaz.

Inicialmente, na seção 2, apresentam-se alguns aspectos relacionados ao processo de ensino-aprendizagem no ensino superior, bem como os modelos possíveis de atividades para o ensino de SIs. Na seção 3, é definida a metodologia utilizada na pesquisa. A análise dos dados, enfatizando os métodos de ensino utilizados para lecionar disciplinas de SIs, a carga horária e os conteúdos de tais disciplinas, é apresentada na seção 4. Finalmente, apresenta-se a conclusão na seção 5.

\section{Revisão da Literatura}

\subsection{O processo ensino-aprendizagem no ensino superior}

A educação de cada região e em cada época é influenciada, ou até revolucionada, por vários fatores, como as exigências do mercado por mão-de-obra qualificada, os fatores de produção, distribuição e consumo de produtos e serviços, além da conjuntura sóciopolítica em que se insere e até mesmo pelo próprio conhecimento humano. A demanda por produção, distribuição e consumo dos produtos influencia na educação, uma vez que geram a necessidade de um certo tipo de mão-de-obra a se formar, que deve ser suficiente à manutenção do comércio e distribuição de produtos, além da expansão sócio-econômica do país. Dessa forma, a educação atende toda a estrutura social e econômica que é atrelada às instituições envolvidas, em especial as de ensino superior. 
As técnicas utilizadas para que o indivíduo alcance esses resultados podem ser denominadas didática, termo que deriva do grego didaktiké, que significa a arte de ensinar. De acordo com Néreci (1989), didática é o conjunto de processos destinados a dirigir a aprendizagem, que é a tarefa principal do professor, considerando também o ponto de vista do educando. Didática é, pois, a conceituação de como levar o educando a alcançar os objetivos da educação.

Segundo Gil (2006), o conceito de aprendizagem é freqüentemente utilizado num sentido muito limitado, pois costuma ser confundido como o de aquisição de conhecimentos. O processo de aprendizagem tem um conceito muito mais amplo, já que se refere a uma ação permanente. De acordo com Gagné (1971), a aprendizagem é alcançada quando ocorre uma mudança ou modificação no comportamento, mudança esta que permanece por períodos relativamente longos.

No processo de ensino-aprendizagem, os conceitos de metodologia, métodos de ensino e técnicas muitas vezes se confundem. A palavra método tem origem no grego nas palavras meta $($ meta $=$ meta) e hodos (hodos $=$ caminho). Segundo Néreci (1989), método quer dizer "caminho para se chegar a determinado lugar". Didaticamente, método é a forma para se alcançar os objetivos estipulados em um planejamento de ensino. Técnica é a substantivação do adjetivo técnico, cuja origem por via do latim está na palavra technunicus, que quer dizer relativo à arte ou conjunto de processos de uma arte ou de uma fabricação. Relacionada a área de ensino, técnica significa como fazer algo, ou seja, como aplicar o método (NÉRECI 1989). Metodologia de ensino, por sua vez, é o conjunto de procedimentos didáticos, expressos pelos métodos e técnicas de ensino, que visam levar a ação didática, sendo esta o alcance dos objetivos do ensino e, conseqüentemente, os da educação com maior eficácia.

A aprendizagem, em uma instituição de ensino superior, tende a ser entendida de modo ainda mais restrito e são escassas as investigações teórico-empíricas que exploram a temática ensino-aprendizagem na área da educação contábil e administrativa (PASSOS, 2006). Apesar dessa limitação, segundo Gil (2006), a eficácia dessa aprendizagem no ensino superior como processo dinâmico depende da metodologia e de múltiplos fatores, relacionadas aos alunos, relacionadas ao professores e relacionadas às organizações do curso.

Dentre os diversos métodos de ensino que embasam o processo de ensinoaprendizagem, Marion (2006) apresenta aqueles que mais se destacam na área de negócios: aula expositiva, exposições e visitas, dissertações, seminários, palestras e entrevistas, discussões e debates, resoluções de exercícios, estudos dirigidos, estudos de casos, jogos de empresa e simulações gerenciais. Observar-se que, devido a limitações ou especificidade da área, os demais métodos não são aplicados nos cursos de Administração e Ciências Contábeis.

\subsection{Modelo possível de atividade para o ensino de Sistemas de Informações}

Segundo Barbanti (2001), a necessidade da constante atualização tem levado as instituições de ensino superior a uma busca por ferramentas que possam auxiliar ao aluno no seu aprendizado, e, o surgimento e o desenvolvimento dos computadores é visto como uma das saídas para auxiliar os professores neste processo de ensinoaprendizagem. A circunstâncias da conjuntura atual movimentam-se com enorme rapidez, e as instituições de ensino superior devem estar preparadas para essa nova 
conjuntura. O profissional atualizado, para sobreviver, tem que se submeter a um processo de reciclagem e estudos dinâmicos, ou seja, atividades práticas.

Segundo Marion (2006), cientistas da comunicação apontam para o fato de que se grava $10 \%$ do que se lê, $20 \%$ do que se ouve, $30 \%$ do que se vê, $50 \%$ do que se ouve e vê, $70 \%$ do que o próprio indivíduo diz e $90 \%$ do que se pratica (atividades práticas). Vale lembrar que há três formas de entender a informação mais facilmente: visual (por meio da visão); auditiva (aprende-se ouvindo); e sinestésica (aprende-se por meio do movimento, do toque, do fazer). Em termos de método de ensino, é sempre aconselhável o uso combinado dessas três formas.

Na área de negócios, as três formas de se entender a informação também se aplicam, mas com uma tendência ao desfavorecimento para atividades práticas. Dessa forma, é mais satisfatório no processo de aprendizagem, atividades práticas para o ensino de SIs, como o desenvolvimento de exercícios propostos pelo professor para realização em sala de aula, ou extra-classe, em que o aluno se envolva tanto na resolução de problemas, quanto na definição teórica para tal, encontrada através da pesquisa.

Uma alternativa para desenvolvimento de atividades práticas, além da realização de exercícios propostos, é a articulação ensino-pesquisa. Essa articulação é necessária para que se alcance ensino de alta qualidade. No processo, tem-se o problema pedagógico com ponto de partida e de chegada, vivenciando interações com o problema identificado com o professor, com os colegas, com textos e materiais audiovisuais diversos.

Visitas em empresas, atividades supervisionadas, estudos de casos e jogos de empresas (simulações), que envolvam prática no desenvolvimento de questões propostas, ou apenas investigação e observação da prática, são atividades possíveis para o ensino de SIs. A estreita relação do ensino com o trabalho é uma das condições essenciais para a superação da dicotomia teoria-prática. (BALZAN 2006).

A estreita relação entre ensino e trabalho é ainda mais evidenciada nos cursos de Administração e Ciências Contábeis. O profissional formado nesses cursos deve estar, cada vez mais, preparado para atuar de forma eficiente no mercado. Dessa forma, os conhecimentos que ele necessita para atuar satisfatoriamente devem ser obtidos durante o curso de graduação.

Uma das dificuldades encontradas nesses cursos é aliar atividades práticas com os conteúdos mínimos essenciais para a formação profissional. Nesse contexto, inserem-se os conhecimentos em SIs. Apesar de serem imprescindíveis para que profissionais em Administração e Ciências Contábeis atuem com eficiência no mercado, a forma como se dá o processo de ensino dos conhecimentos em SIs não garante a aprendizagem. Isso porque, muitas vezes, no processo de ensino-aprendizagem não se reúnem teoria e prática, ou seja, os conteúdos essenciais com o desenvolvimento de atividades práticas. 


\section{Metodologia}

Os dados foram coletados inicialmente com o uso de um questionário aplicado a uma amostra de alunos de graduação em Administração e Ciências Contábeis na Universidade Federal de Minas Gerais. Em seguida, realizou-se um roteiro de entrevista com os professores que lecionam disciplinas de Sistema de Informações (SIs) nesses cursos na UFMG, assim como um roteiro de entrevistas com os coordenadores dos dois cursos.

Os dados foram coletados junto a todos os alunos matriculados nas disciplinas de SIs ministradas nos cursos. O questionário aplicado aos alunos é composto de questões fechadas. Essas questões foram definidas visando obter informações sobre quais métodos de ensino são utilizados para lecionar disciplinas de SIs nos cursos de graduação em Administração e Ciências Contábeis na UFMG e como esse métodos são utilizados, além de informações sobre a situação atual das disciplinas de SIs de uma forma geral. Em algumas questões procurou-se obter respostas classificatórias, e, para tanto, utilizou-se a Escala Lickert. Estas questões foram analisadas utilizando-se recursos da estatística descritiva, com o objetivo de efetuar uma análise confirmatória dos dados, o que foi realizado com o auxílio do software Excel. Segundo Cooper e Schindler (2003, p. 604), “a análise confirmatória de dados refere-se a um processo de análise que utiliza a inferência estatística clássica para obter os resultados”.

Os professores que lecionam disciplinas de SIs nesses dois cursos foram entrevistados. O roteiro de entrevistas junto aos professores era composto de questões que visavam obter informações sobre os métodos de ensino utilizados por eles para lecionar disciplinas de SIs nos cursos de graduação em Administração e Ciências Contábeis na UFMG. Além disso, buscou-se obter informações sobre a situação atual das disciplinas de SIs nos dois cursos. As questões desse roteiro foram analisadas através da análise de conteúdo. De acordo com Westbrook (1994, p. 245), a análise de conteúdo caracteriza-se como "um método de pesquisa que utiliza procedimentos para tornar válidas determinadas inferências a partir do texto”. Para Cullinane e Toy (2000, p. 42), “a análise de conteúdo é um conjunto de instrumentos de pesquisa para o estudo científico de comunicações escritas, com o objetivo de determinar idéias chave e temas contidos nessas comunicações”.

O roteiro de entrevistas junto aos coordenadores dos cursos teve como objetivo destacar a percepção destes perante a carga horária, atividades desenvolvidas, métodos de ensino utilizados e a realidade atual das disciplinas de SIs.

\section{Análise dos dados}

As informações sobre a grade curricular dos cursos foram retiradas das ementas das disciplinas no primeiro semestre do ano de 2006. A última versão da grade curricular de Administração entrou em vigor no primeiro semestre do ano de 1996. Para Ciências Contábeis, a última versão da grade curricular entrou em vigor no segundo semestre de 1998.

Na pesquisa, de acordo com os alunos abordados do curso de Administração, os métodos de ensino mais utilizados pelos professores são: exposição ( $81 \%$ dos alunos), trabalho em grupo (81\%), e explicação (77\%). Os alunos do curso de Ciências Contábeis abordados consideram que os métodos de ensino mais utilizados pelos 
professores são: exposição (76\% dos alunos), explicação (73\%) e estudos de caso (70\%).

Dentre os vários métodos de ensino citados na pesquisa, alguns deles se destacam por serem utilizados pela maioria dos professores, e, em especial, o método de aula expositiva. Em todas as entrevistas realizadas, os professores afirmaram lecionar a maior parte das aulas através da exposição de temas. Dessa forma, observa-se que os professores investem a maior parte das aulas em exposições teóricas, sendo então atribuído às disciplinas relacionadas a SIs um caráter basicamente teórico.

Ainda na pesquisa, foi questionado aos coordenadores dos cursos como as disciplinas de SIs inseriam-se no currículo dos cursos. Os coordenadores afirmaram que as disciplinas de SIs são importantes a administradores e contadores. Em relação à percepção dos professores sobre a importância dos SIs para a formação profissional em Administração e Ciências Contábeis, a maioria dos entrevistados afirmou que os conhecimentos em SIs são fundamentais.

Em relação aos alunos, foi questionado se as disciplinas de SIs diferenciam a formação profissional de administradores e contadores. No curso Administração, 34\% concordam parcialmente com a afirmação; e, 43\% são indiferentes. No curso de Ciências Contábeis, 24\% dos alunos concordam totalmente que as disciplinas de SIs diferenciam a formação profissional de contadores; 30\% concordam parcialmente; e, 33\% são indiferentes;

Os três grupos de entrevistados afirmaram sobre a importância das disciplinas de SIs para os profissionais da área, como estas diferenciam e colaboram para a formação de administradores e contadores. Apesar da relevância apontada, observa-se que não há uma integração definida formalmente entre as disciplinas de SIs e as demais disciplinas dos cursos. Isso limita, de certa forma, a contribuição das disciplinas de SIs para a formação profissional.

Ainda na pesquisa, os alunos foram questionados a respeito da carga horária das disciplinas de SIs. 51\% dos alunos de Administração concordam parcialmente que a carga horária seja satisfatória, 37\% dos alunos de Ciências Contábeis têm essa opinião. Em relação aos professores, questionou-se também sobre tal assunto. A maioria dos professores (60\%) considera que 60 horas é uma carga horária pequena. Os demais a consideram satisfatória, porém afirmam que deveriam ser ministradas mais disciplinas relacionadas a SIs. Aos coordenadores dos cursos de graduação em Administração e Ciências Contábeis foi questionado se essa carga horária é adequada/ suficiente comparativamente às outras disciplinas. Os dois coordenadores afirmaram que a carga horária das disciplinas que tratam de SIs é adequada/ suficiente.

De acordo com o método de ensino utilizado, os tópicos abordados pela disciplina, a carga horária e o número de alunos em classe, um apropriado grupo de recursos é necessário para uma otimização das aulas. Dessa forma, foi questionado aos três grupos de entrevistados (alunos, professores e coordenadores) quais são os principais recursos necessários às disciplinas de SIs. Em relação aos equipamentos de informática (laboratório), 63\% dos alunos do curso de Administração e 69\% dos alunos de Ciências Contábeis consideram-nos uma das principais necessidades das aulas das disciplinas de SIs. 55\% dos alunos do curso de Administração consideram que softwares profissionais atualizados sejam uma das principais necessidades, enquanto 
que 78\% dos alunos de Ciências Contábeis têm essa opinião. 74\% dos alunos de Administração e 76\% dos alunos de Ciências Contábeis consideram que simuladores de sistemas das empresas reais sejam uma das principais necessidades nas aulas das disciplinas de SIs, no que tange aos recursos que deveriam ser disponibilizados.

Em relação aos professores, a maioria citou sobre a quantidade de alunos por classe, além das acomodações físicas das salas de aula. Citou-se também a necessidade de equipamentos de informática (laboratório), data show, softwares profissionais atualizados, retro-projetores em todas as salas.

Aos coordenadores foi questionado se eles consideravam importante a disponibilidade de laboratórios de informática e de sistemas de informações comerciais para estas disciplinas. Os entrevistados afirmaram que consideram importante a disponibilidade de laboratório de informática e dos sistemas de informações que são utilizados pelas empresas (sistemas de informações comerciais). O coordenador do curso de Administração ponderou sobre a necessidade de que os sistemas de informações comerciais sejam disponíveis no laboratório e que sejam gratuitamente cedidos pelas empresas como exemplos de aplicação.

Ainda assim, de acordo com o método de ensino utilizado e recursos disponibilizados, existem limitações para sua aplicação em sala de aula. Dessa forma, questionou-se aos alunos se existem limitações aos métodos de ensino utilizados para ministrar as disciplinas de SIs. No curso de Administração, 57\% consideram que existem limitações aos métodos de ensino utilizados para ministrar disciplinas de SIs. No curso de Ciências Contábeis, 72\% consideram que existem limitações aos métodos de ensino utilizados para ministrar as disciplinas de SIs.

Ainda em relação às limitações aos métodos de ensino, os professores entrevistados citaram que o número de alunos por disciplina, as precárias acomodações físicas, restrições de número de máquinas no laboratório de informática e a necessidade de assistência da tecnologia e de hardware e software atualizados, além de televisões, melhor qualidade do acervo da biblioteca e do maior número de exemplares são limitações aos métodos de ensino que utilizam. Um dos professores afirmou que o corpo docente composto por um número reduzido de doutores é uma limitação encontrada.

Por fim, os alunos foram questionados sobre as possíveis melhorias a serem realizadas nas disciplinas de SIs. No curso de Administração, 56\% dos alunos consideram que uma das possíveis melhorias a serem realizadas nas disciplinas de SIs é em relação aos equipamentos de informática; já no curso de Ciências Contábeis, 65\% dos alunos têm essa opinião. 59\% dos alunos do curso de Administração consideram que uma das possíveis melhorias a serem realizadas nas disciplinas de SIs é em relação a softwares profissionais atualizados, enquanto que $85 \%$ dos alunos do curso de Ciências Contábeis têm essa opinião. $71 \%$ dos alunos do curso de Administração consideram que uma das possíveis melhorias a serem realizadas nas disciplinas de SIs seja em relação a prática em laboratório de informática; no curso de Ciências Contábeis, $74 \%$ dos alunos têm essa opinião. No curso de Administração, 60\% dos alunos consideram que uma das possíveis melhorias seja em relação ao uso de softwares profissionais no laboratório de informática, e 76\% dos alunos do curso de Ciências Contábeis têm essa opinião. 
Concluindo a entrevista, professores e coordenadores comentaram sobre a realidade atual das disciplinas de SIs nos cursos de graduação em Administração e Ciências Contábeis na UFMG. A maioria dos professores entrevistados afirma que, de uma fora geral, a realidade das disciplinas de SIs é satisfatória, uma vez que "várias disciplinas tratam de perspectivas diferentes de sistemas", sendo "suficientes para que um administrador e contador". Outros, porém, comentaram que as disciplinas relacionadas a SIs poderiam ter uma carga horária maior, devida a grande importância na formação profissional do aluno, além de necessidade "trabalhar na inter-relação das disciplinas de SIs com demais disciplinas, e melhor dotar a instituição com recursos tecnológicos”. O coordenador do curso de Administração considerou que as disciplinas de SIs "estão sendo reformuladas no âmbito do novo projeto pedagógico".

\section{Conclusão}

Os Sistemas de Informações (SIs) são de fundamental importância para a tomada de decisão em uma empresa, pois possibilitam a transformação de dados em informações úteis e confiáveis. As empresas necessitam de profissionais preparados, que possuam em seus currículos conteúdos de SIs que os capacitem para a gestão eficaz das informações necessárias ao processo decisório. Este estudo apresenta uma análise dos métodos de ensino utilizados para lecionar disciplinas relacionadas com SIs nos cursos de graduação em Administração e em Ciências Contábeis da Universidade Federal de Minas Gerais. Os resultados encontrados indicam que, em ambos os cursos, o ensino de SIs apresenta limitações.

A pesquisa foi realizada com alunos, professores e coordenadores dos dois cursos e aponta que o ensino de SIs apresenta algumas limitações, principalmente no que tange aos recursos disponibilizados pela universidade. Para os alunos de Administração, o ensino de SIs não apresenta grandes entraves. Por sua vez, os alunos de Ciências Contábeis apontaram como principal dificuldade a não disponibilidade de computadores e projetores em sala de aula, o que auxiliaria enormemente a assimilação do conteúdo ministrado.

Para os professores, são várias as limitações para o ensino de SIs nos dois cursos. Dentre as citadas, foram apontadas como principais as seguintes: a ausência de softwares atualizados, a precariedade dos recursos físicos disponibilizados pela universidade, além da dificuldade de conciliar o interesse dos alunos com os métodos de ensino. Nesse caso, o que normalmente acontece é uma dicotomia entre as preferências metodológicas dos alunos e aquelas prioritariamente utilizadas para o ensino de SIs.

A opinião dos coordenadores dos cursos é, de certa forma, divergente. Segundo o coordenador do curso de Ciências Contábeis, as principais limitações são a falta de bibliografia nacional especializada, o uso informal do laboratório, e a necessidade de mais disciplinas de SIs no currículo. De acordo com o coordenador do curso de Administração, a principal limitação está ligada aos conteúdos das disciplinas. Segundo ele, deveria haver um tópico voltado exclusivamente para a introdução à utilização de sistemas de apoio à tomada de decisão em administração.

Conclui-se que, embora o ensino de SIs seja fundamental para a formação profissional de administradores e contadores, ainda há diversas limitações neste processo. As principais dificuldades estão relacionadas aos recursos físicos e à falta de interdisciplinaridade das disciplinas de SIs às demais disciplinas dos dois cursos. 
Contudo, parece que grande parte dos pesquisados compreende a importância de um ensino de qualidade dessas disciplinas para uma boa formação profissional.

\section{Referências}

BARBANTI, Marta de Campos Maia. Estudo sobre a informática no ensino de administração de empresas. In: Enanpad,2001

BIREAUD, Annie. Os métodos pedagógicos no ensino superior. Porto: Porto Editora, 1995.

COOPER, Donald R.; SCHINDLER, Pamela S. Métodos de Pesquisa em Administração. 7. ed. Porto Alegre: Bookman, 2003.

CULLINANE, Kevin; TOY, Neal. Identifying influential attributes in freight route/mode choice decisions: a content analysis. Transportation Research Part E: Logistics and Transportation Review. v. 36, p. 41-53, março 2000.

GAGNÉ, Robert M. Como se realiza a aprendizagem. Rio de Janeiro: Livros Técnicos e Científicos, 1971.

GIL, Antonio Carlos. Didática no ensino superior. São Paulo: Atlas, 2006.

GIMENES, Régio Marcio Toesca; BERNARD, Ricardo Rodrigo Stark. Uma proposta metodológica para a implantação das técnicas de simulação empresarial associadas a construção e aplicação de sistemas de informações gerenciais e de apoio às decisões nos cursos de graduação em administração. Angrad. Apresentado no VII Congresso del Instituto de Costos. 2001. Disponível em <http://www.angrad.org.br/>.

LAUDON, Kenneth C.; LAUDON, Jane Price. Sistemas de Informação. 4. ed. Rio de Janeiro: LTC, 1999.

MARION, José Carlos, MARION, Arnaldo Luís Costa. Metodologias de ensino na área de negócios: para curso de administração, gestão, contabilidade e MBA. São Paulo: Atlas, 2006.

NÉRECI, Imídeo Giuseppe. Metodologia de ensino: uma introdução. $3^{\mathrm{a}}$ ed. São Paulo: Atlas, 1989.

O’BRIEN, James A., Sistemas de informação: e as decisões na era da Internet. São Paulo: Saraiva, 2002.

PASSOS, Ivan Carlin. Métodos de Sucesso no Ensino da Contabilidade. In: CONGRESSO USP CONTABILIDADE, 3ㅜ 2006. São Paulo.

SOUZA, Francisco Luciano de. Uma Interface entre a Teoria da Decisão e a Contabilidade. $1^{\circ}$ SEMINÁRIO USP, 2001. São Paulo.

STAIR, Ralph M., REYNOLDS, George W. Princípios de Sistemas de Informação uma abordagem gerencial. São Paulo: Pioneira Thomson Learning, 2006.

TURBAN, Efraim; RAINER JR., R. Kelly; POTTER, Richard E. Administração da tecnologia da informação - teoria e prática. Rio de Janeiro: Campus, 2005.

WESTBROOK, Lynn. Qualitative research methods: a review of major stages, data analysis techniques and quality controls. LISR. v. 16, p. 241-254, 1994. 